\title{
Contradiction analysis: towards a dialectical approach in ergonomics field interventions
}

\author{
Dimitris Nathanael ${ }^{a *}$, Nikos Zarboutis ${ }^{\mathrm{b}}$, Nicolas Marmaras ${ }^{\mathrm{c}}$ \\ ${ }^{a *}$ dnathan@central.ntua.gr, NTUA, Greece \\ bnikos@worksystems.gr, ELVAL Colour S.A./WORKSYSTEMS Engineering, Greece \\ ‘marmaras@central.ntua.gr, NTUA, Greece
}

\begin{abstract}
The present paper is a methodological contribution to the ergonomics field intervention process. It proposes a perspective on work analysis based on the dialectics notion of contradictions. Contradiction analysis is proposed as being complementary to more established work decomposition methods. The aim of including such an analysis is to frame various heterogeneous determinants of a work activity in practical terms, swiftly and in a manner that preserves its multifaceted unity and essence. Such framing is of particular value when considering alternative design solutions because it provides a practical means for anticipating the effects and side effects of proposed changes. The proposed method is inspired by two theoretical constructs: (i) contradiction, as used in Cultural Historical Activity Theory, and (ii) regulation, as developed and used by the francophone tradition of the ergonomics of activity. Two brief examples of its use are presented, and its usefulness, possible pitfalls and need for further developments are discussed.
\end{abstract}

Keywords

Work design \& organization. Action research. Macroergonomics. Activity theory.

\section{Introduction}

Intervening in a real work-situation is almost always a challenging experience. Where does one start from? In most cases there is of course an explicit request, an initial problem to address, but still, how does one go about tackling a complex reality? More often than not, in real work situations, concerns, complaints, dilemmas and stakes are so intermingled -sometimes positive in one respect and negative in another- that when one tries to get hold of them, s/he rapidly feels overwhelmed by the complexity. Obviously, the generic ergonomics formulation of analyzing the fit between worker abilities and task demands does not make things any simpler.

The common way to proceed is to try to analyze by decomposing elements of a work situation -either in structural, functional or temporal terms-. For example, a clerical work will typically be decomposed in the physical morphology of the workstation, the informational demands of the work and probably the organizational imperatives. The three components will be examined one by one, the first dealing with the aspects of physical health, the second with aspects of mental fatigue and/or mistakes, while the third possibly with psychosocial stress, etc. This strategy, although systematic, tends to lead to a fragmented view of work. Fragmentation often results to incremental improvements in each of the decomposed elements. Although in line with Ergonomics and Human Factors handbooks, such an approach often fails to identify key issues or even the essence of a particular work situation. For example, in the clerical task, the complex interaction between cognitive effort, informational demands and postural comfort may easily be overlooked. In the same manner, when a work situation is decomposed in temporal terms, e.g. in phases, one may fail to identify important interdependencies or conflicts between determinants that manifest themselves at different time scales, e.g. long term health vs. short term comfort or production quantity vs. safety, etc. 
For example, a particular routine performed over and over again by a worker might appear inefficient or irrational to an external observer. However, this seeming inefficiency could possibly hide a longstanding safety concern (warranted or not). In fact, no concrete methodological tools exist to tackle the complex nonlinear interaction between the multiple exigencies and needs of different nature that happen to co-exist in the same work reality. This is one of the reasons why the so called "ergonomic standards or databases" are often marginally applicable in practice.

The above critique is definitely not new; it forms part of a more general debate concerning the systems approach of ergonomics as a discipline (Wisner, 1995; Meister, 1999; Wilson, 2012). Needless to say, it is also clear that such critique does not imply that an experienced ergonomist will necessarily fail to identify complex issues once s/he adopts a decomposition approach; it merely suggests that decomposition approaches do not promote the identification of multi-level or multi-thematic interdependencies.

The present paper aims to contribute to the methodological toolset of the ergonomics intervention process by proposing and demonstrating a "hands on" dialectical analysis of work activity in terms of contradictions. We intend to show that such a method of analysis and representation may help frame the essence of a work activity in practical terms, and in a manner that highlights its multifaceted unity. The proposed conceptual tool is inspired by Dialectics and borrows from two theoretical constructs; i) regulation, as developed and used by the francophone tradition of ergonomics of activity and ii) contradictions as defined in Cultural Historical Activity Theory (CHAT).

The structure of the paper is as follows: in the next sections we present the concept of contradictions and related notions used in the work analysis literature, focusing particularly in the regulation notion and the contradictions as used by CHAT. After presenting some methodological issues, two case studies will be used in order to demonstrate our approach for "contradiction analysis" in industrial projects. Finally, we discuss the possible merits of the approach and its limitations as well as the way forward.

\section{The concept of contradictions}

Dialectics, as a process of thought considers order in systems as a dynamic equilibrium, as the recurring result of an active straggle between diverse internal tensions. These internal tensions are more often than not represented as sets of opposing forces or contradictions. The term contradiction as employed in Dialectics, does not equate its more common definition used in formal logic, i.e. the logical incompatibility between two or more propositions; it does not point to an objectively impossible thing (Wilde, 1992). In Dialectics, contradiction is defined as a set of opposing tendencies inherently existing within one realm, one unified force or object; in other words, a contradiction is identified whenever two tendencies are interdependent -inherently united- yet mutually negating or undermining one another.

Typical contradictions from the domain of ergonomics are:

- Inside the human body: physiological fatigue vs. musculoskeletal health. For example, in a typical repetitive lifting task, metabolic data suggest that it is more efficient to lift heavier weights less frequently than to lift lighter weights more frequently. On the other hand, biomechanical studies show that lifting lighter weights more frequently reduces muscle and vertebral stress (Waters et al., 1993). This suggests that between certain limits, the two criteria are contradictory.

- On how people understand and conduct at work: adherence to procedures or flexible coping. Many times workers face such dilemmas i.e. whether to comply with procedures or perform according to what they believe is right at the moment. In the ergonomics literature there is plethora of examples where compliance to a procedure may happen to be in conflict with the contingencies of real work (Wright et al., 1998; Montmollin, 1999; Nathanael \& Marmaras, 2008).

- In human values: financial incentives vs. accident risk. For example, empirical as well as epidemiological evidence exists that links a per piece remuneration scheme in industrial workers with an increased risk of accidents (Johansson et al., 2010).

All the examples above point to forces that, up to a certain degree, undermine one another yet they are expressed as belonging to one unified realm, as unavoidably unified. It is important to disambiguate between the notion of contradiction and that of a conflict. ldentifying a tension between two forces as a conflict one necessarily takes sides, because a conflict needs to define two realms. On the other hand, identifying a tension between two forces as a contradiction, one presses himself to express them in their interconnectedness, in their unity. A perceived conflict can often be conceptually transformed into a contradiction if the analyst succeeds in expressing the two forces in one united realm. This mental exercise typically entails a move upwards in the systemic structure of work. For example, an identified conflict between two shifts of workers in an industrial production line may be transformed in a contradiction if understood at the level of production planning 
(e.g. allocating the most demanding production lots to the best performing team). Note though that the concept of contradiction goes well beyond the conceptual reformulation of a conflict between two agencies. Contradictions may well be identified inside an undividable agency as an individual worker. One may thus identify a contradiction between skill development and immediate performance in the activity of a certain individual. Such "personal" contradictions may or may not be conscious to the individual involved.

\section{The concept of contradictions in the work analysis literature}

In the ergonomics literature we may find plethora of notions and concepts that tackle phenomena of complex and often-conflicting interactions between work determinants. In fact ergonomics per se can be defined by a set of opposing dualities or contradictions. Take for example one of the cornerstones of its definition, the "compatibility" between task demands and worker abilities. In classic view of ergonomics, the duality "task demands vs. worker abilities" is formulated as a question of fit, i.e. "are the worker's abilities enough to deal with the demands of the task?" or, vice-versa "is the task at hand adapted to the workers' abilities?" The classic view if taken literally is rather simplistic. It fosters a one to one comparison between demands and abilities, e.g. between the aerobic work capacity of a person and the energy demands of a particular task, or between one's ability to withstand acceleration and the acceleration characteristics of a vehicle. In fact, the worker abilities - task demands compatibility model is useful only in extreme and prototypical situations, e.g. when someone needs to lift a heavy object, run a particular distance or perform a set of calculations, etc.

In the work analysis literature specifically, one important school of thought that pushed forward the traditional compatibility model was the Francophone school, starting with the seminal work of Faverge (1966). Faverge, inspired from cybernetics, introduced the analysis of activity in terms of regulation, as one of the four types of activity analysis (the other three being (i) analysis in terms of gestures, (ii) analysis in terms of information, and (iii) analysis in terms of mental processes). According to Faverge (1966) workers and/or teams at work often regulate between partly conflicting or contradictory requirements, e.g. immediate production vs. overall system objectives, or, following of one rule vs. the following of another, or even fatigue vs. safety.
The concept of regulation in the analysis of activity provided a cybernetic reformulation of the basic duality between task demands and worker abilities. In the regulation concept, the basic duality still holds in the form of internal resources and needs vs. external demands, but it is no longer formulated as a question of fit; rather it is formulated as deliberate "coping”. Regulation adds three important elements to the classic view: (i) that internal resources and task demands are not one-dimensional (i.e. they form a system), (ii) that there is always ability to give slack between the two (i.e. temporarily exceed nominal limits), and (iii) that the worker will freely exploit this slack (see Guerin et al. (2007), for a comprehensive overview of the approach)

In contemporary analyses of activity the worker is generally considered as an active agent who constantly balances between internal resources and external exigencies. In this line of thought we encounter notions such as balance between internal needs and external demands (Leplat, 2000), double rationality (Dejours, 1995), margins of maneuver (De La Garza \& Weill-Fassina, 2000), shifting between operating modes (Sperandio, 1972), invariance structure, constraints, boundaries of acceptable performance (Rasmussen et al., 1994), etc. All these notions, stemming from the tradition of ergonomics of activity, point to the fact that in concrete situations i) there is no unequivocal path of what has to be done at any moment, ii) work goals are multi-dimensional often fuzzy and neither subjectively nor socially neutral, and iii) that the working people are free to exploit or need to resolve the remaining ambiguity. That is, at any moment the workers either need to make conscious decisions or unconsciously regulate between diverging goals and/or internal needs.

The concept of regulation is a systems dynamics formulation that can functionally model a great variety of real work situations that are characterized by the principal opposition between individual resources (and needs) vs. external demands, but also worker regulation between conflicting external determinants. In a way the concept of regulation in activity is a manifestation of coping (conscious or not) of the workers in the face of contradictions. Thus, beyond theoretical subtleties between the two concepts, regulation can be understood as a functional counterpart of contradictions in individual or group activity. However, of most importance in this concept is that it acknowledges regulation as a true concern (i.e. an object of work) for the worker. The acknowledgement of this process as an objective and legitimate object of workers' concern was a major contribution of the Francophone school of ergonomics. 
Another school of thought that analyses work activity in similar terms is the Cultural Historical Activity Theory (CHAT). In CHAT activity is represented structurally as a system of interrelated elements. Rather than the regulation dynamics, the structural tensions between elements are clearly mapped and termed contradictions. Contradictions in CHAT are directly inspired from Dialectic Materialism and are defined as objective tensions that may both hinder and facilitate the historical development of an activity system (Engeström, 1987; Nardi, 1996). Typically in CHAT contradictions are identified and categorized according to the basic structure of the activity system (i.e. between the subject, object, tools, division of labor, rules and community), between different activities, or within an activity's different developmental stages (Engeström, 1987). CHAT maintains the theoretical position that contradictions are not mere inefficiencies of an activity system to be alleviated by corrective measures. According to CHAT, contradictions unavoidably exist in activity systems, being the primary mechanism for their dynamism and transformation. In our view, the proposition of conceiving contradictions as an underlying process of change of an activity system is an important contribution of CHAT in ergonomics thinking.

\subsection{Generic vs. Concrete contradictions}

Whether adopting a dialectic perspective or not, there is a growing number of authors in Human Factors / Ergonomics who present key notions as contrasting dualities rather than as simple propositions. For example, the latest thinking in resilience engineering posits that safety is not an independent system quality, i.e. for a given level of system resources, safety cannot be drastically improved unless productivity goals are at least partially compromised (Hollnagel, 2009). In the same vein, it has also been observed that chronic goals tend to get sacrificed to acute goals. These observed contradictions between productivity and safety have been formulated as the EfficiencyThoroughness trade-off and the Acute - Chronic trade-off (Woods, 2009).

Hoffman \& Woods (2011) go as far as to propose five fundamental trade-offs for what they call "macro cognitive work systems". These are: OptimalityResilience trade-off, Efficiency-Thoroughness trade-off, Acute-Chronic trade-off, Specialist-Generalist trade-off and Distributed-Concentrated trade-off. These bi-poles of opposing tendencies can be identified in many work situations, and may provide entry questions in a dialectical approach to work analysis. However, generic categories of contradiction, although informative, may be less effective in accounting for the plurality and particularity of conflicting forces in any concrete work situation.

In a concrete situation contradictions may be identified as a struggle not only between mutually incompatible external exigencies but also between antagonistic internal resources. For example, as we remind above, in many heavy manual work situations one may identify an intra-subjective contradiction between musculoskeletal health and physiological fatigue, or one may identify a conflict between personal values that manifest themselves whenever long term health effects are in contrast to financial gains (as in self-employed, or per piece remunerated workers). One may thus encounter situations where an internal need is aligned with some external demand but in contradiction to other -usually longer terminternal needs. All these examples may easily be categorized under the Acute - Chronic fundamental trade-off. However, such categorization apart from being a theoretical umbrella, that provides uniformity across cases, does little to clarify the specifics of each concrete reality. Generic types of contradiction have an undeniable demonstrative and educational value, but their unreflective use may obscure the particular tensions of any concrete situation. One thus starts to question the usefulness of applying any generic typology of contradiction in concrete situations.

The core idea in the proposed analysis of contradictions is that invariants in human activity at work can parsimoniously be represented by sets of contradictions inherent in the activity of the human(s) in his / her (their) situation. When first encountering a work-system, an analyst may start to recognize such sets of contradictions based on:

(i) Manifestations of instability or irrationality in the system. For example, oscillations in performance, differing working styles among workers or teams, disputes between co-workers, inconsistencies in people's accounts etc., all are points of entry for a contradiction analysis;

(ii) Analyzing the history of the work situation and particularly changes that have occurred across time, as well as the rationale behind them (Nathanael \& Marmaras, 2005);

(iii) Analyzing formal and informal responsibilities and goals against the formal organizational structure may also provide fast hints.

There is actually no determining sign of an underlying contradiction other than some kind of fuzziness or concern. However, behind such fuzziness or concern there is almost always a trade-off or choice to be made, a choice that is neither simple nor settled. Moreover, such choices may appear at different levels of a work-system from intra-individual bodily choices, individual cognitive, motivational, 
workstation, work-team or organizational level. It is at this point that generic types of contradiction may play a role in directing the analyst's focus.

In the following section we present two cases where contradiction analysis facilitated problem description and problem solving in our interventions. The case studies are drawn from the authors' professional consulting work in industrial projects. In both case studies the authors were the ones who both planned and executed the interventions. In both cases the primary aim was not academic but practical. The descriptions are short and lacking in detail but we hope that the ergonomics practitioner will complement them with parts of his own experience. The case studies come from two different domains, namely:

(a)Wind Turbines maintenance activities

(b)Cement Silo Trucks drivers' activity

\section{Demonstration of contradiction analysis through case studies}

\subsection{Wind Turbine maintenance}

A company who provides maintenance services to Wind Turbine farms put up a request to address the growing safety concerns coming from safety audits. In fact, the audits were showing that service technicians who physically perform the maintenance of turbines were adhering less and less on standard safety procedures.

Wind turbine (W/T) maintenance is a hard and risky activity. W/T service technicians need to have specific mechanical and electrical knowledge, along with acrobatic abilities and physical endurance. They work at remote places, in teams of two, at the top of the $\mathrm{W} / \mathrm{Ts}$ (at 50 to 100 meters height), where they usually have to climb by themselves, lifting also their tools and spares (Figure 1). The physical environment is characterized often by extreme weather conditions, and at times by low frequency oscillations of the pylons. Service technicians may spend several hours on top of the W/T performing delicate and lengthily tasks.

Service technicians' work is directly dependent from the service dispatcher. The service dispatcher is the person who manages the maintenance schedules. In order to better understand the forces influencing the service technicians' work, one has to understand the work of the dispatcher as well. The dispatcher's activity is characterized by the regulation between diverse requirements, set out by interacting:

- Upwards, with the Wind Farm owner, by regulating the trade-off between profit loss minimization -as servicing requires the $\mathrm{W} / \mathrm{T}$ to be switched off-, and the need to perform the $\mathrm{W} / \mathrm{T}$ maintenance according

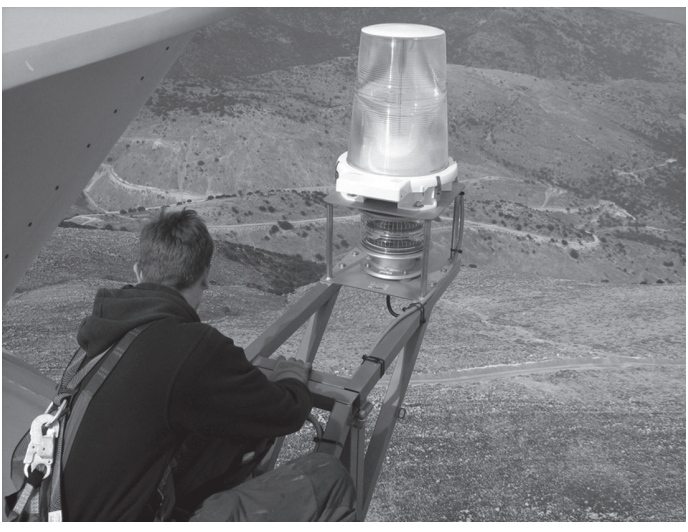

Figure 1. The W/T service technician at work.

to the manufactures time limits. The dispatcher needs to preserve an availability rate of $99.7 \%$ uptime (availability below $99.7 \%$ results in claims). The management of this trade-off dynamically determines a time-window where-in all maintenance activities have to be carried-out (e.g. arranging that each W/Ts' maintenance will be performed in less windy conditions, thus resulting to low energy yield).

- Downwards, with the service process itself, in an escalating manner:

i. Initially trying to maximize personnel utilization (e.g. by minimizing technician time spent on each $\mathrm{W} / \mathrm{T}$ ), and at the same time trying to ensure an acceptable quality of maintenance;

ii. Interacting with the technicians and the way they are actually carrying out the maintenance activity (e.g. tackle unexpected problems, spare part delays, etc.).

Coming to the service technician, his main task is undoubtedly the carrying out of technical maintenance of W/Ts. In this particular company W/Ts are assigned to specific technicians, thus each technician is responsible for the quality of maintenance of his W/Ts. In fact, each technician's performance is closely assessed based on his W/Ts uptime levels. Technicians, apart from executing the W/T maintenance tasks as written in the manuals, must regulate between several needs and demands which often contradict one another. Specifically:

- On the one hand service technicians try to satisfy the schedule as given by the dispatcher. As it was already shown, this schedule is moderated dynamically by the dispatcher, resulting to a demand for servicing each turbine within strict duration limits and schedule constraints. Moreover schedule may change with little prior notice as they are heavily dependent on weather conditions. On the other hand, service technicians press for more time on every W/T striving for thoroughness. This striving for thoroughness is closely linked with two mutually reinforcing determinants: 
The allocation of W/T to specific technicians and their assessment according to the levels of their W/T uptime. This fact alone pushes technicians towards being more thorough than fast.

The technicians' own needs and personal values (i.e. decrease of physical fatigue and the sentiment of pride when "his" wind turbines function properly).

One way for the service technician to resolve the contradiction between the schedule imposition and the need for a thorough job, is to cut-down on non appraised tasks. In the service technicians' environment such time consuming or fatiguing tasks are the ones related to safety measures. For example, shortcuts like the use of one, instead of two, lanyards to secure themselves or performing a task with a non-reliable tool (because of the time and effort needed to hoist the proper one), are typical. Being alone at 50-100 meters height, the service technician has full personal responsibility for his safety but also full discretion to follow safety procedures or not.

In fact the service technician finds himself in a type of efficiency - thoroughness contradiction set out by the organizational structure of his work. At times, when he is unable to resolve it (due to tiredness or time constraints), he compromises thoroughness by pressing on the only aspect of his job where he has full control and discretion, i.e. his personal safety. He thus transforms the above contradiction into service quality vs. personal safety or into a personal comfort vs. personal safety one.

The formulation and explicit representation of the nested set of contradictions above (see Figure 2) defined a frame to work on, when trying to intervene in the work of the service technician. Specifically the above analysis has served (i) as an entry point for a sincere and open relation with service technicians, (ii) as a negotiation platform between technicians - dispatcher and management and (iii) as a guiding tool for anticipating the possible effects and side-effects of various anticipated measures. For example the analysis, although not unanimously accepted, made it clear that imposition measures for adhering to safety procedures would be totally inadequate. This was also the case for possible training measures. The intervention team concentrated i) on technical improvements (e.g. tools and lifting apparatus) and ii) on a more flexible and interactive scheduling between dispatcher and $\mathrm{W} / \mathrm{T}$ technicians. Higher level imperatives such as profit and W/T uptime were considered but obviously not altered.

\subsection{Silo-trucks circulation}

In a cement production factory, a request was initiated from the factory management to re-design the vehicle traffic inside the plant. There are two types of vehicles circulating inside the plant, internal plant vehicles and external silo-trucks. Problems in traffic were mostly associated with the silo-trucks. The situation was characterized by management as disordered and lacking formal separation rules for vehicle traffic.

In this particular plant, cement in powder form is being loaded into silo-trucks and transported nationwide to customers' facilities. Twenty-six (26) privately owned silo-trucks ensure this transportation, each one having a separate contract with the plant. During the day silo-trucks arrive to the plant to load from two (2) loading hoses on a first-come-firstserved fashion. A total number of six (6) designated parking places are assigned by the plant for this purpose. However, these six places are rarely enough. Most of the time the workplace transport system is congested because of trucks moving and stopping
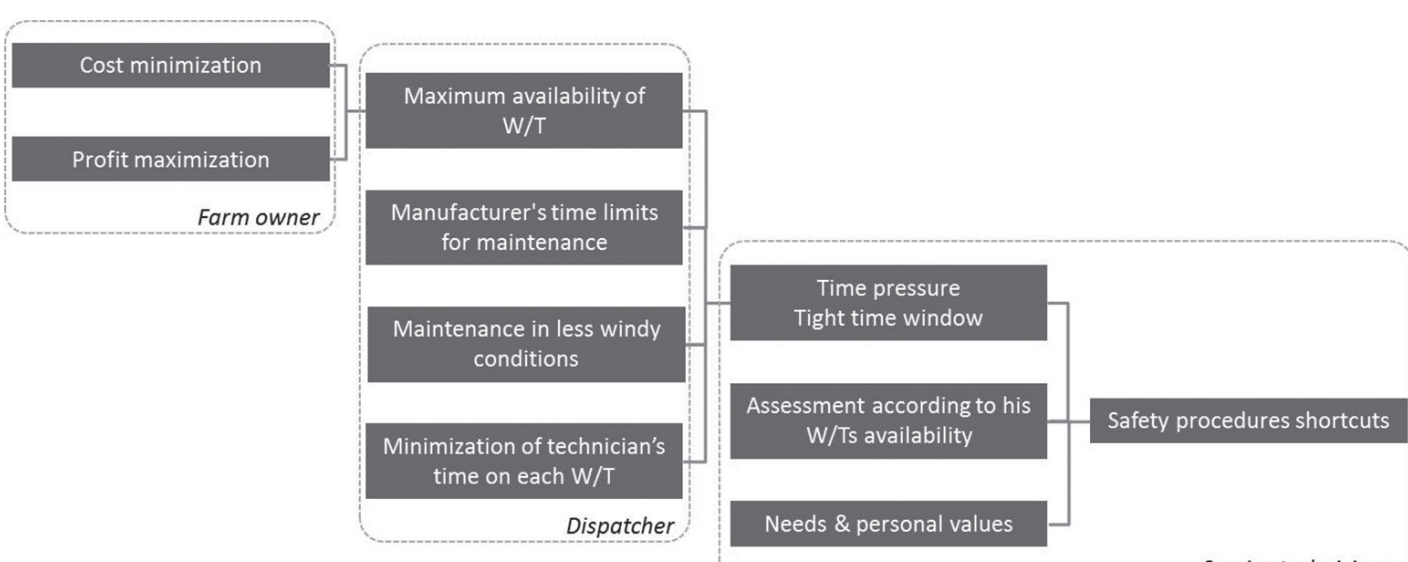

Figure 2. Summary of Contradiction Analysis for the case of Wind Turbine Maintenance. 
within the plant (Figure 3). It is important to note that in this particular plant, free space is scarce with various departments demanding more.

Various factors that play a role in the resulting situation may be identified. These span across the systemic structure of work, from work system wide factors to individual ones, and across time, from historically developed to day-to-day ones. The most prominent factors, as identified by the intervention team, are outlined below:

- The plant's management had made a decision long ago to outsource cement delivery to clients. The primary aim in outsourcing cement delivery was to ensure timely transport according to demand (i.e. silo-truck availability) without the burden to manage its own silo-trucks (saving on purchase, maintenance, drivers' salaries, needed parking space, etc.). This decision unavoidably entailed a compromise in the control over silo-truck scheduling and presence on the plant.

- The production manager favors silo-trucks standing-by inside the plant. In this way he always has spare capacity to immediately satisfy orders shipment. On the other hand, silo-trucks standing-by tend to compromise internal vehicle transport capacity and safety. This tension between maximum silotruck availability vs. traffic capacity determines the total number of silo-trucks "wanted" by the plant at a given time. However, since both demand and delivery times vary a lot, the number of silo-trucks waiting on the site easily exceeds the desired one.

- As already noted, silo-truck drivers, work as independent contractors and typically strive to increase their revenue (i.e. deliver as many loads as possible during a day). Since the system operates on a 'first-come-first-served' fashion, drivers, after each delivery, rush back to get a good spot in the queue. To this end, drivers often park their trucks disorderly, even staying overnight or arriving very early before the plant opens, causing problems also on a national artery passing in front of the plant. In fact, in the current system, the only force that contradicts this tendency is drivers' personal need for rest and natural dislike of long waiting times. Since the total volume of cement to be shipped is determined externally, silo-truck drivers are pushed into an antagonism with each-other with detrimental effects, both for their activity in the long term and for the vehicle circulation inside the plant. Therefore, a basic contradiction in the silo-truck drivers' activity is manifested by the trade-off between maximizing revenue vs. satisfying their personal lives and chain of values (i.e. work-hours per day, driving instead of waiting for long, disputes with other drivers, etc.).

As a rectification to the vehicle circulation problem, the company management was envisaging three measures: i) strict designation of silo truck routes

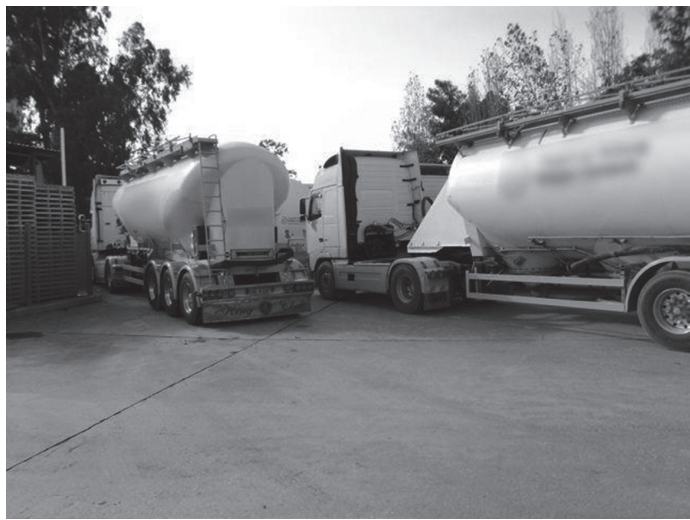

Figure 3. Cement silo trucks waiting to load.

inside the plant, ii) the provision of a limited number of additional parking spaces on a near by site, and iii) reprimands to drivers that failed to comply with company policy (i.e. entailing a risk for their contract).

A number of interviews with drivers as well as with production people allowed us to frame the problem in rather different terms. Specifically, one basic contradiction in the company management's activity was created by the decision to outsource cement delivery. Saving recourses went side by side with a decreased level of foresight and control on fleet of silo-trucks. Second, another basic contradiction was created by the production management's requirement for untroubled shipment of cement even at peak demand. This requirement with the current model went side by side with creating havoc in the plants' traffic. The measures envisaged by the company management were not going to resolve the problem. It was neither a problem stemming from unfamiliarity of truck drivers of the plant nor a problem stemming from some 'indiscipline nature' of drivers. Also any additional parking space far from the loading stations would prove almost pointless by itself. Actually, by not considering carefully the determinants (motives and constraints) of silo-truck drivers' activity, but also their close link to the shipment pressures from production, the management would embark in corrective measures that would not touch the underlying etiology of the problem.

Amelioration of the workplace transport system needed to address the interaction between the following contradictions (see Figure 4):

- control on silo-trucks fleet and schedule vs. level of invested capital;

- silo-truck availability vs. congested traffic inside the plant;

- silo-truck drivers' profit vs. dislike in waiting and long working hours. 


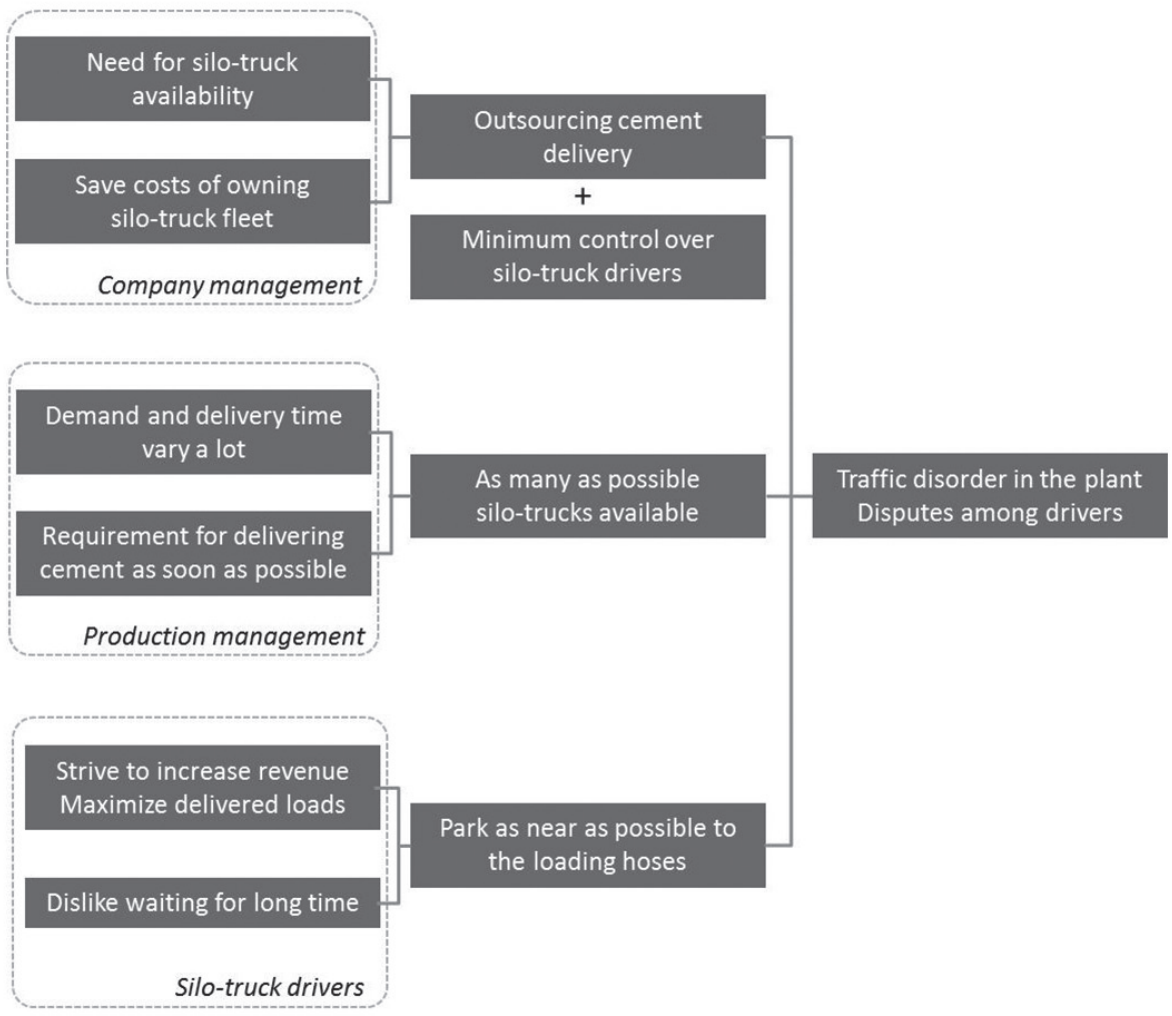

Figure 4. Summary of Contradiction Analysis for the case of Silo-Trucks Circulation.

By constructing the above perspective on basic work system contradictions, the intervention team set the basis for a negotiation platform and for directing further analyses and solution ideas. For example it was proposed to investigate the use new mobile communication technologies to allow for better correspondence between shipment needs and selfmanagement by drivers. Higher level contradictions (i.e. centralized control of schedules vs. invested capital), although not affected, nonetheless they facilitated in altering the higher management's initial normative perspective.

\section{Discussion}

Developing such a contradiction analysis is neither straight forward as a process nor unequivocal in its results across different analysts. After all each ergonomics intervention is a construction and as such it always develops in an original and not replicable way. Nevertheless we have been surprised how representations such as the above made immediate sense between different ergonomists but also, and more importantly, that they were accepted as relevant and meaningful by most stakeholders in the projects above.

We came to believe that if an ergonomist develops a perspective of work activity as coping within a space of diverging and often conflicting forces, a high level model of activity can be swiftly constructed. Our analysis explicitly avoids categorizing "types of contradictions" such as the ones used in CHAT. It messes up internal tensions (within an individual) with external inter-individual conflicts. From our reflective practice we came to the conclusion that it is not so the typology that matters but the perspective. Analyzing work-systems in terms of contradictions can help ergonomic interventions in the following ways:

- it defines a frame of reference for the ergonomist to place new issues upon;

- it ensures that the ergonomist has explicitly searched and captured the core issues from the initial stages of the analysis;

- its revisions provide a logbook of the ergonomists' evolution of understanding the activity;

- it can serve as a collective representation and negotiation tool between stakeholders (if the worksystem climate permits it);

- it serves as a reference for anticipating the probable effects and side-effects of possible design interventions.

For the time being we cannot provide concrete methodological guidance on the process. We can only point to the following prioritized hints: First 
and foremost the analyst should search for issues that can be identified -with insider's aid- as persistently significant for the worker(s) at a particular work situation (i.e. the main articulable concerns of the worker(s) at a particular moment and time frame). Second, the analyst should search for issues that can be identified as invariant bi-poles of the objective (extrinsic) structure of the work situation; these bi-poles not only constrain but have a persisting, determining effect on worker's conduct. Third, s/he should pay attention to observed phenomena such as routine deviations from procedures, oscillations in worker's conduct, anxiety, fluctuation in the work results etc. as these may hide unarticulated or non-articulable concerns.

All the above can be attributed either to extrinsic factors of the work situation (e.g. formal goal structure, external demands vs. internal needs) or as understanding of what is -believed to be- experienced by the working individual or collectivity. The above hints are in fact just alternative ways of approaching contradictions, i.e. techniques that can be employed at the initial phase of a "contradiction analysis".

Since the method is still indefinite and will always remain partly vague by definition, the ergonomist may easily fall into traps. For example, s/he may be tempted to elevate contradictions analysis at a level higher than s/he can influence (e.g. political \& societal level), or on the other side of the spectrum to interpret any minor issue that s/he encounters as a contradiction and getting "drowned" in a dialectical analysis of self-evident reality. The art of this trade for any analyst is, on the one hand, to stay inside the envelope of her/his possibilities for a positive impact (e.g. to self restrain from elevating his contradiction analysis to a political or societal level) and, on the other hand, to restrain from getting drowned in the dialectics of self-evident reality.

Future efforts to advance the method will concentrate on the following directions: i) development of heuristics for identifying contradictions and for stopping the analysis, ii) theoretical progress in understanding and conceptualizing the dynamic character of contradictions as an intervention or design effort unfolds.

\section{References}

De La Garza, C., \& Weill-Fassina, A. (2000). Régulations horizontales et verticales du risque. In A. Weill-Fassina \& T. H. Benchekroun (Eds), Approches ergonomiques $d u$ travail collectif dans les systèmes socio-techniques (pp. 271-234). Toulouse: Octares.

Dejours, C. (1995). Le facteur humain. Paris: PUF.

Engeström, Y. (1987). Learning by expanding: an activitytheoretical approach to developmental research. Helsinki: Orienta-Konsultit Oy.
Faverge, J.-M. (1966). L'analyse du travail en termes de régulation. In J.-M. Faverge, M. Olivier, J. Delahaut, P. Stephaneck \& J. C. Falmagne, L'ergonomie des processus industriels (pp. 33-60). Bruxelles: Éditions de l'Institut de Sociologie.

Guerin, F., Laville, A., Daniellou, F., Duraffourg, J., \& Kerguelen, A. (2007). Understanding and transforming work: the practice of ergonomics. Ed. ANACT.

Hoffman, R. R., \& Woods, D. D. (2011). Beyond Simon's Slice: Five Fundamental Trade-Offs that Bound the Performance of Macrocognitive Work Systems. IEEE Intelligent Systems, 26(6), 67-71. http://dx.doi.org/10.1109/ MIS.2011.97

Hollnagel, E. (2009). The ETTO Principle: Efficiencythoroughness trade-off: Why things that go right sometimes go wrong. London: Ashgate.

Johansson, B., Rask, K., \& Stenberg, M. (2010). Piece rates and their effects on health and safety - A literature review. Applied Ergonomics, 41(4), 607-614. PMid:20106469. http://dx.doi.org/10.1016/j.apergo.2009.12.020

Leplat, J. (2000). L'analyse psychologique de l'activité en ergonomie. Toulouse: Octarès. PMid:10976864.

Meister, D. (1999). The History of Human Factors and Ergonomics. Mahwah: Erlbaum.

Montmollin, M. (1999). Analysis and models of operators activities in complex natural life environments. Produção, 9(spe), 29-42. http://dx.doi.org/10.1590/ S0103-65131999000400002

Nardi, B. A. (1996). Context and Consciousness: Activity Theory and Human-computer Interaction (pp. 1-20). Cambridge: MIT Press.

Nathanael, D., \& Marmaras, N. (2005). Historical analysis as a means to uncover the dynamics of evolving practices. In Proceedings of the 25th Annual Conference of the European Association of Cognitive Ergonomics, Chania.

Nathanael, D., \& Marmaras, N. (2008). On the development of work practices: a constructivist model. Theoretical Issues in Ergonomics Science, 9(5), 359-382. http:// dx.doi.org/10.1080/14639220701596706

Rasmussen, J., Pejtersen, A. M., \& Goodstein, L. P. (1994). Cognitive Systems Engineering. New York: John Wiley $\&$ Sons.

Sperandio, J. C. (1972). Charge de travail et régulation des processus opératoires. Le Travail Humain, 35, 85-93.

Waters, T. R., Pulz-Anderson, V., Garg, A., \& Fine, L. G. (1993). Revised NIOSH equation for the design and evaluation of manual lifting tasks. Ergonomics, 36, 749-776. PMid:8339717. http://dx.doi. org/10.1080/00140139308967940

Wilde, L. (1992). Logic: Dialectic and Contradiction. In T. Carver (Ed.), The Cambridge Companion to Marx. Cambridge: Cambridge University Press.

Wilson J. R. (2012). Fundamentals of systems ergonomics. Work, 41, 3861-3868. PMid:22317311.

Wisner, A. (1995). Understanding problem Building: ergonomic work analysis. Ergonomics, 38(3), 595-605. http://dx.doi.org/10.1080/00140139508925133

Wright, P. C., Pocock, S., \& Fields, R. E. (1998). The prescription and practice of work on the flight deck. In Proceedings of the Ninth European Conference on Cognitive Ergonomics, Limerick.

Woods, D. D. (2009). Escaping Failures of Foresight. Safety Science, 47, 498-501. http://dx.doi.org/10.1016/j. ssci.2008.07.030 